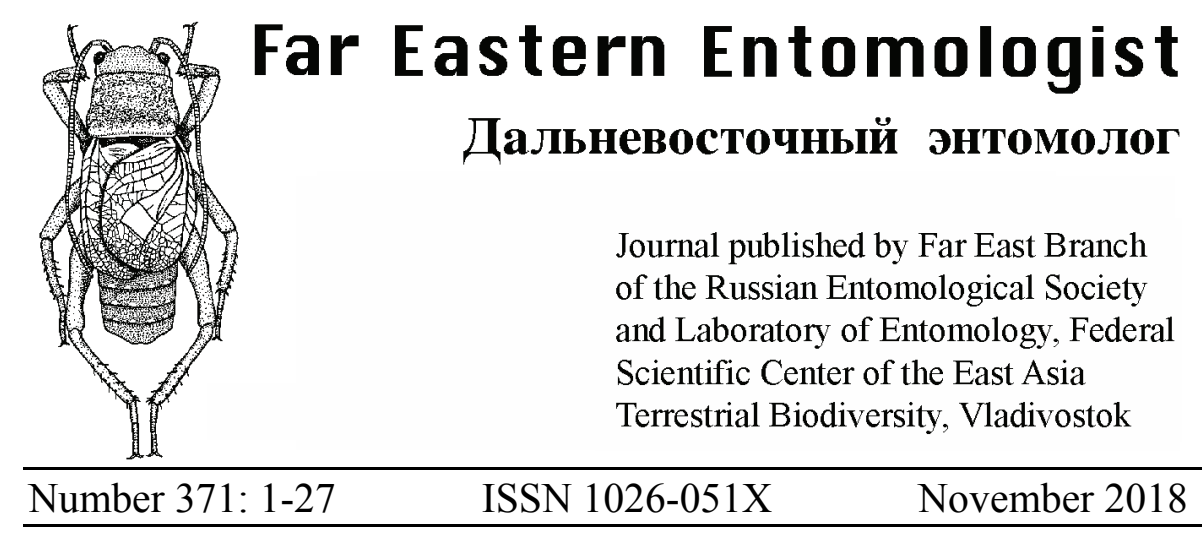

Journal published by Far East Branch of the Russian Entomological Society and Laboratory of Entomology, Federal Scientific Center of the East Asia Terrestrial Biodiversity, Vladivostok

\begin{tabular}{lll}
\hline Number 371: 1-27 ISSN 1026-051X & November 2018 \\
\hline
\end{tabular}

https://doi.org/10.25221/fee.371.1

http/urn:lsid:zoobank.org:pub:B59F1915-556B-4DCC-B0FD-3257945A2183

\title{
NEW SPECIES OF CHRYSIDIDAE (HYMENOPTERA) FROM CENTRAL ASIA, RUSSIA AND IRAN. PART 1
}

\section{P. Rosa}

Via Belvedere 8/d I-20881 Bernareggio (MB), Italy.E-mail: rosa@chrysis.net

Summary. Ten new species are described: Cleptes transoxianus sp. n. (Kazakhstan), Philoctetes pavesii sp. n. (Kazakhstan), Holopyga lucens sp. n. (Turkmenistan, Uzbekistan), Hedychridium kilimniki sp. n. (Kazakhstan), Hedychridium fadeevi sp. n. (Kazakhstan), Chrysis leleji sp. n. (Russia: Altai), Chrysis kazenasi sp. n. (Kazakhstan), Chrysis gertiana sp. n. (Iran, Turkmenistan), Chrysis fastigiata sp. n. (Kazakhstan), Chrysis diadema sp. n. (Turkmenistan).

Key words: cuckoo wasps, taxonomy, new species, Palaearctic region.

П. Роза. Новые виды ос-блестянок (Нуmenoptera: Chrysididae) из Центральной Азии, России и Ирана. Часть 1 // Дальневосточный энтомолог. 2018. N 371. C. 1-27.

Резюме. Описывается 10 новых для науки видов: Cleptes transoxianus sp. n. (Казахстан), Philoctetes pavesii sp. n. (Казахстан), Holopyga lucens sp. n. (Туркменистан, Узбекистан), Hedychridium kilimniki sp. n. (Казахстан), Hedychridium fadeevi sp. n. (Казахстан), Chrysis leleji sp. n. (Россия: Алтай), Chrysis kazenasi sp. n. (Казахстан), Chrysis gertiana sp. n. (Иран, Туркменистан), Chrysis fastigiata sp. n. (Казахстан), Chrysis diadema sp. n. (Туркменистан). 


\section{INTRODUCTION}

After extensive study of the Russian Chrysididae (Rosa et al., 2017c, d, e, f, g, h; Rosa, 2018) the attention was paid to the chrysidid fauna of the Central Asia. The recent examination of unsorted chrysidids housed at the Zoological Institute of St. Petersburg (Russia) resulted in finding of several underscribed species from Central Asia (Kazakhstan, Kyrgyzstan, Tajikistan, Turkmenistan, Uzbekistan), and southern Russia (Altai). Additional specimens from Iran have been found in Linsenmaier's collection (Luzern, Switzerland).

Only few articles have been published on Central Asian chrysidids so far, and only two countries have been somewhat investigated: Tajikistan (Semenov \& Nikol'skaya, 1954) and Kyrgyzstan, only for Chrysidini (Tarbinsky, 2000a, b, 2001, 2002a, b, c, 2004). O. Radoszkowski (1820-1895) first studied the Chrysididae fauna of Central Asia, describing about 20 new species (Rosa et al., 2015). A. Mocsáry (1841-1915), the most influential author of his times, described 46 Central Asian species and provided new distributional data for several Asian species (Rosa et al., 2017a). A. Semenov-Tian-Shanskij (1866-1942) was certainly the most productive author, having described 220 species and varieties; three of his most famous papers (Semenov, 1954, 1967; Semenov \& Nikol'skaya, 1954) were published posthumously after his death, in 1942. Ten further species were described by W. Linsenmaier (1917-2000), based on chrysidids collected by W.J. Pulawski in Turkmenistan (1968). Lastly, Yu. Tarbinsky (1937-2004) reviewed the Chrysidini of Tian-Shan, describing 46 species (2000a, b, 2001, 2002a, b, c, 2004).

To date, 423 species and subspecies have been recorded for Central Asian countries: 168 for Kazakhstan, 146 for Kyrgyzstan, 144 for Tajikistan, 148 for Turkmenistan, 141 for Uzbekistan, and 60 were generally cited for "Turkestan", without precise localities, therefore impossible to correctly locate. I consider also six species described by Radoszkowski from Saraks, locality previously considered in Iran (Khorasan), yet possibly referable to the Saraks oasis (Ahal Province) in Turkmenistan, both placed on the border between the two countries.

I here describe 10 new species belonging to five genera (Cleptes Latreille, 1802; Hedychridium Abeille de Perrin, 1878; Holopyga Dahlbom, 1845; Philoctetes Abeille de Perrin, 1879; Chrysis Linnaeus, 1761), whereas further ones will be described in the following issue of this journal.

\section{MATERIALS AND METHODS}

Specimens were examined and described under a Carton Togal stereomicroscope. Photographs of specimens were taken with Nikon D-3400 connected to the stereomicroscope Togal SCZ and stacked with the software Combine ZP. Morphological terminology follows Kimsey \& Bohart (1991). Abbreviations used in the descriptions as follows: F1, F2, F3, etc. $=$ flagellomere 1, 2, 3 and so on; $\mathbf{M O D}=$ midocellus diameter; $\mathbf{M S}=$ malar space, the shortest distance between base of the mandible and the lower margin of compound eye; $\mathbf{O O L}=$ the shortest distance between posterior 
ocellus and compound eye; $\mathbf{P}=$ pedicel; $\mathbf{P D}=$ puncture diameter; $\mathbf{P O L}=$ the shortest distance between posterior ocelli; $\mathbf{P P W}=$ propodeum posterior width.

Types are deposited at the Zoological Institute of St. Petersburg (ZIN), NaturMuseum Luzern, Switzerland (NMLS), Paolo Rosa's private coll. (PRC).

\title{
DESCRIPTION OF NEW SPECIES
}

\author{
Subfamily Cleptinae
}

Genus Cleptes Latreille, 1801

\section{Cleptes transoxianus Rosa, sp. $\mathbf{n}$.}

Figs 1-4

SPECIMENS EXAMINED. Holotype - + , Kazakhstan: Vanovka, $80 \mathrm{~km}$ E of Dzhambul [currently Taraz], 30.VI 1992, leg. M. Halada [ZIN].

DIAGNOSIS. Cleptes transoxianus sp. n. belongs to the $\mathrm{Cl}$. nitidulus species group, based on the pronotum without posterior pit row and without longitudinal median sulcus. $\mathrm{Cl}$. transoxianus sp. n. at first sight resembles $C$. morawitzi Radoszkowski, 1877 from Central Asia, for its coloration, with head and mesosoma partly flame red and metasoma dark. However it can be easily separated for propodeum and metasoma, both black with more or less expanded metallic red to purplish reflections (mesosoma fully red and metasoma fully deep black in C. morawitzi). Other two Asian species, Cl. mareki Rosa, 2003 and Cl. helanshanus Wei, Rosa \& $\mathrm{Xu}, 2013$, both described from China, have black metasoma, yet their head and mesosoma are almost entirely black with bluish (C. mareki) or with golden reflections (C. helanshanus). C. transoxianus sp. n. can be also easily separated from $C$. morawitzi for the shortened pronotum (distinctly elongate in C. morawitzi) and the subrectangular shape of clypeal margin.

DESCRIPTION. Female. Holotype. Body length $6.1 \mathrm{~mm}$ (Fig. 1). Forewing length $4.0 \mathrm{~mm}$. POL = 2.5 MOD; OOL = 2.4 MOD. MS = 12 MOD. P:F1:F2:F3 = 1.0:1.1:0.9.

Head. Face and vertex with small, even, and sparse punctures (1-4 PD). Clypeal lower margin convex, 1 MOD width, without acute teeth at corners. Frontal sulcus broad and deep, complete from midocellus to clypeal margin (Fig. 3), deeper and broadened below midocellus. Mandibles bidentate. Ocellar triangle isosceles, without post-ocellar sulcus. Postero-lateral pits close to hind ocelli deep, rounded, as large as 0.5 MOD. Pedicel slightly shorter than F1. Malar spaces elongate (2.4 MOD), subparallel.

Mesosoma. Pronotum unmodified, shortened, without transverse row of pits on posterior margin and without longitudinal median groove; with small punctures similar to those on vertex, yet even sparser. Mesoscutum and mesoscutellum scarcely punctate, with small and scattered punctures (more than 6 PD), with medial, broad, impunctate, and shining area; notauli and parapsidal lines complete. 
Mesopleuron with small punctures; on posterior half with a short, deep scrobal sulcus (Fig. 2); on anterior half with punctures, somewhere confluent in transverse striae; medially with single and sparse punctures. Metanotum with two large foveae

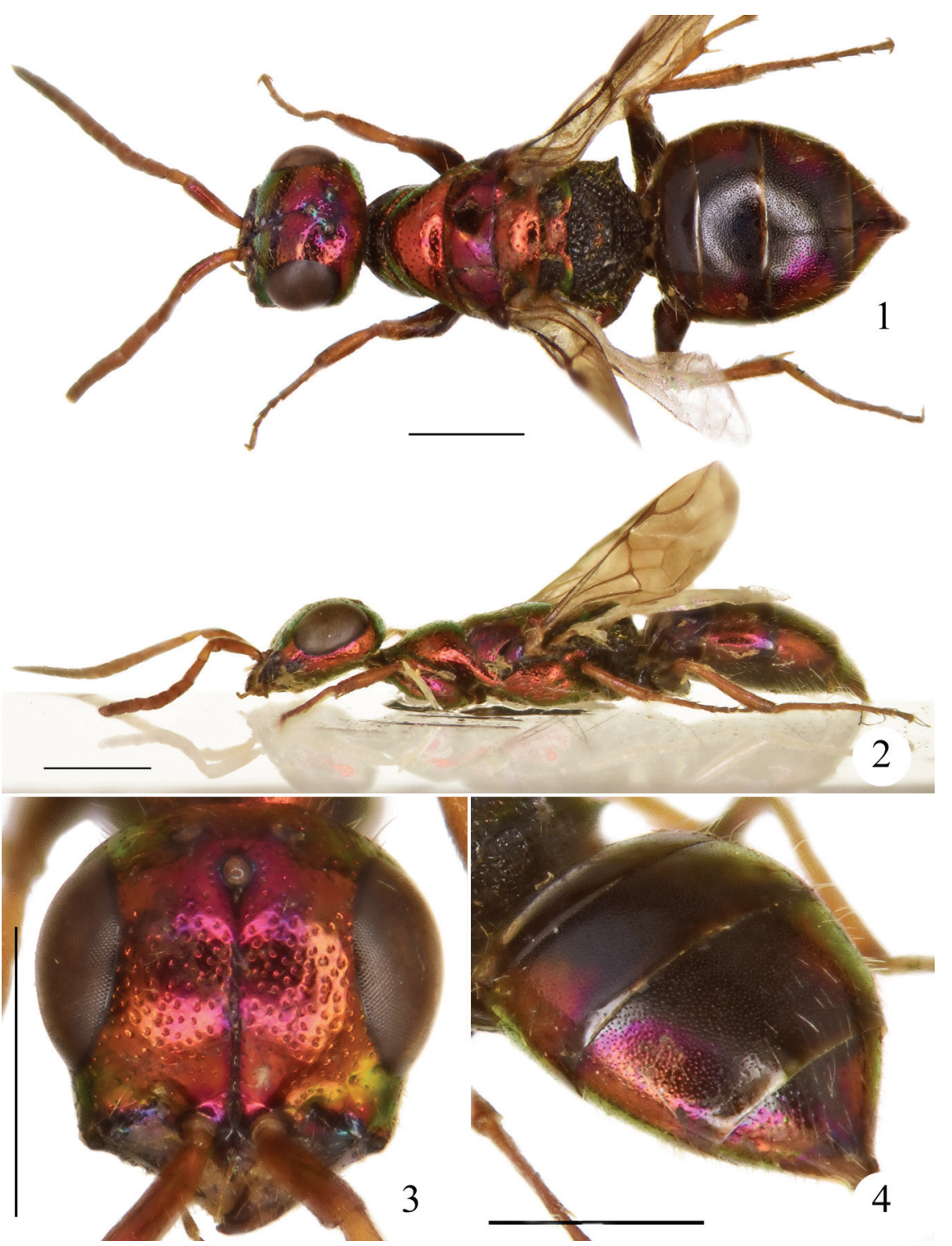

Figs 1-4. Cleptes transoxianus Rosa, sp. n., holotype $\bigcirc$ : 1 - habitus, dorsal view; 2 habitus, lateral view; 3 - head, frontal view; 4 - metasoma, dorso-lateral view. Scale bar $=$ $1.0 \mathrm{~mm}$. 
along posterior margin; axillary trough longitudinally irregularly striate. Metapleuron transversely striate. Dorsal surface of propodeum short, irregularly reticulate. Propodeal angles short, stout, and divergent (Fig. 1).

Metasoma. Metasomal terga densely punctate, with small punctures, posteromedially impunctate; all terga with impunctate stripe along posterior margin (Figs $1,4)$; laterally with double punctation; punctures on fourth tergum sparser.

Coloration. Head and thorax metallic red to purplish; propodeum black, with medial, ill-defined metallic red spot. Metasoma medially black, laterally metallic red to purple. Antennae testaceous to yellowish, scape with opalescent reflections. Tegulae metallic violet. Fore femora, except for joints, metallic violet, mid- and hind femora brown; tibiae testaceous, with opalescent reflections, tarsi testaceous. Metasoma ventrally with purplish reflections.

Vestiture. Head on vertex and clypeus with short (1.0-1.5 MOD), sparse, whitish setae. Metasoma laterally and posteriorly, on third and fourth tergum, with long (5 MOD) sparse, erected, whitish setae.

Male. Unknown.

DISTRIBUTION. Kazakhstan.

ETYMOLOGY. The specific epithet is named after Transoxiana, the ancient Latin name used for the portion of Central Asia corresponding approximately with modern-day southwest Kazakhstan, Kyrgyzstan, Tajikistan and Uzbekistan.

\section{Subfamily Chrysidinae}

\section{Tribe Elampini}

Philoctetes pavesii Rosa, sp. n.

Figs $5-10$

SPECIMENS EXAMINED. Holotype - $\widehat{\text { t}}$ : Kazakhstan: env. of Kapchagay, 13.IX 1987, leg. V. Kazenas [ZIN].

DIAGNOSIS. The coloration of Philoctetes pavesii $\mathbf{s p .} \mathbf{n}$. is somehow similar to that of Ph. horvathi (Mocsáry, 1889), yet is easily identifiable for the metascutellum rounded in lateral view, and the apical margin of the third tergum continuous, medially without notch. It is separated from other Asian species with similar coloration (Ph. deauratus (Mocsáry, 1914), Ph. mongolicus (du Buysson, 1901) and Ph. cynthiae Rosa, 2017) for the round metascutellum (conical in Ph. deauratus and distinctly projected backward in Ph. mongolicus and Ph. cynthiae) and the smooth apical margin of third metasomal tergum (with shallow, in Ph. deauratus, or deep median notch, in Ph. mongolicus and Ph. cynthiae).

DESCRIPTION. Male. Holotype. Body length $4.7 \mathrm{~mm}$. OOL = 1.4 MOD; POL $=2.3 \mathrm{MOD} ; \mathrm{MS}=1.0 \mathrm{MOD}$; relative length of $\mathrm{P}: \mathrm{F} 1: \mathrm{F} 2: \mathrm{F} 3=1.0: 1.3: 1.0: 0.8$. F11 as long as pedicel.

Head. Frons, vertex, face between eye and scapal basin with small (about 0.3 MOD), shallow (Fig. 6), sparse (up to 3-4 PD) punctures, with tiny dots on interstices. 

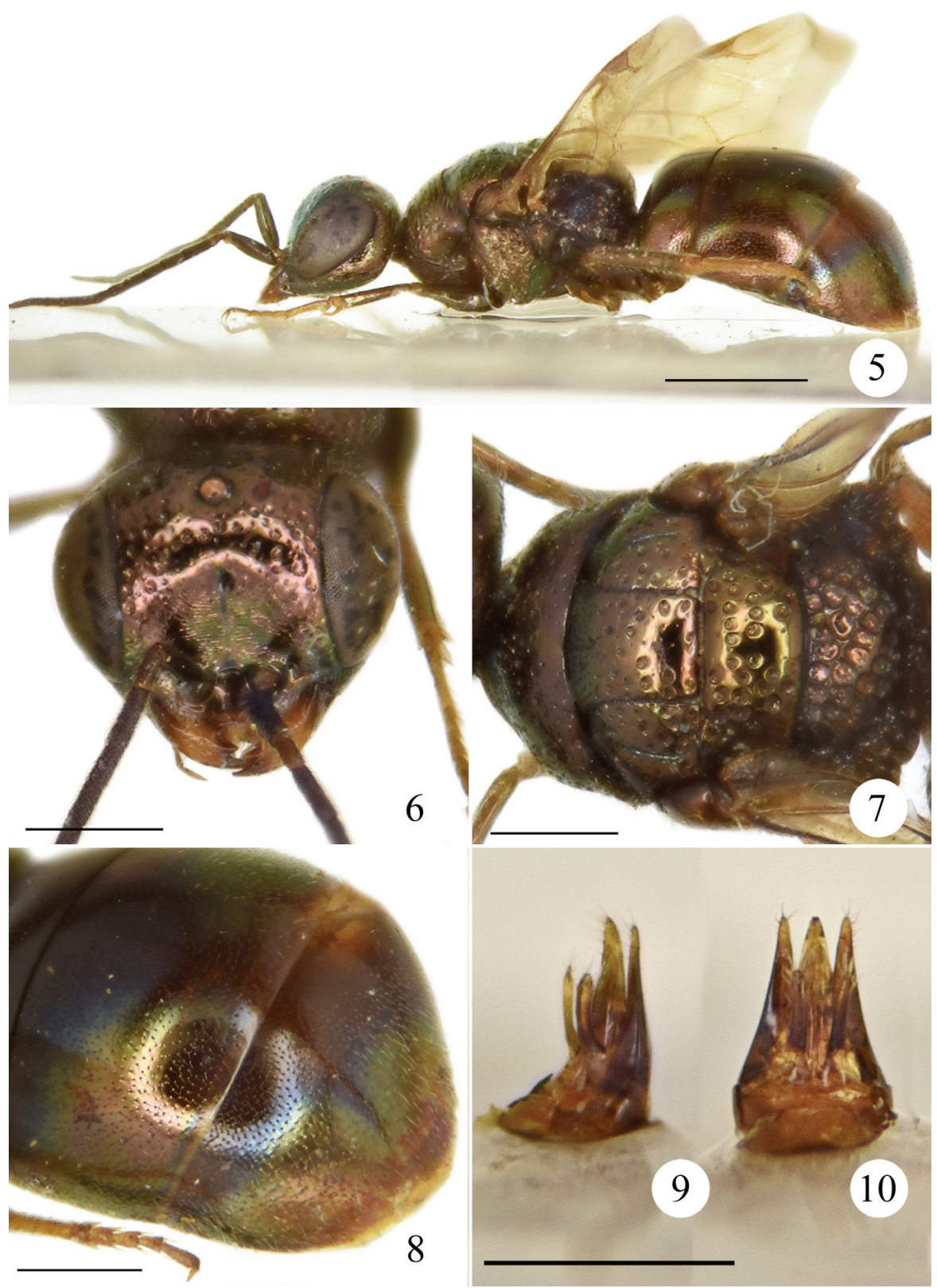

Figs 5-10. Philoctetes pavesii Rosa, sp. n., holotype $\widehat{\jmath}: 5$ - habitus, lateral view; $6-$ head, frontal view; 7 - mesosoma, dorsal view; 8 - metasoma, dorso-lateral view; 9 - genital capsula, lateral view; 10 - genital capsula, ventral view. Scale bar $=1.0 \mathrm{~mm}$. 
Scapal basin asetose, slightly hollowed, medially with weak transverse wrinkles and smooth above (Fig. 5). Genae with tiny punctures, without wrinkles. Genal carina faint. Ocellar triangle isosceles, postocellar line deep and complete; broad POL and short OOL. Mandibles bidentate.

Mesosoma. Punctation on pronotum similar to the one on vertex, with small and sparse punctures, broad interspaces and tiny dots within; on sides with larger and deeper punctures. Mesoscutum with larger punctures, mostly clumped along notauli, with increasing diameter towards mesoscutellum; interspaces broad and shining, with sparse and tiny punctures all over; notauli visible as lines of small punctures; parapsidal furrows incomplete, anteriorly and posteriorly obsolete; mesoscutal median area baso-medially polished. Mesoscutellum punctures slightly larger (up to 0.5 MOD), sparse, baso-medially polished. Metascutellum with large (1.0 MOD), irregular punctures; round in lateral view (Fig. 5). Propodeal angles triangular and slightly pointing outwards. Mesopleuron with large punctures; omaulus and scrobal carina well distinct. Tarsal claw apically bidentate. Genitalia dark brown, with lighter volsella.

Metasoma. Metasoma finely punctate, with even, tiny punctures, equally spaced all over terga; apical margin of metasomal terga with broad, hyaline rim, well visible at the apex of the third tergum, the latter medially continuous, without notch. First two sterna and lateroterga polished, third sternum with dense, tiny punctures. Genital capsule as in Figs 9, 10.

Coloration. Body bronze, with pinkish reflections (Fig. 5); metasomal terga dorsally with large dark blue to brown-blackish spot; metasomal sterna nonmetallic, brown. Tegulae brown. Legs bronze with greenish reflections, tarsi yellowish to light brown. Antennae black. Mandibles brown, lighter medially and darker at apex.

Female. Unknown.

DISTRIBUTION. Kazakhstan.

ETYMOLOGY. The species is named after Maurizio Pavesi (Natural History Museum, Milan, Italy), who supported my studies on Chrysididae in the last years.

\section{Holopyga lucens Rosa, sp. n.} Figs 11-14

SPECIMENS EXAMINED. Holotype - $\lesssim$, Uzbekistan: Kashkadarya, Muborak district, $5 \mathrm{~km} \mathrm{~S}$ of Muborak, 39¹8'31'’N 6508'19'’E, 15.V 2015, leg. Mokrousov, Proshalykin, Samartzev [ZIN]. Paratypes: Turkmenistan: st. Akhcha-Kujma, 5.VII 1934, 1ð̄, leg. V. Popov, Holotypus H. lucens sp. n. Sem. \& Nik. [ZIN]; Askhabad, 10.VI 1928, 1ð̂, leg. V. Gussakowskij [ZIN]; Karabata, 7.VI 1932, $2 \hat{\jmath}$, leg. Kuziakin [ZIN, PRC]; Askhabad, bordure du desert, 28.V 1964, 1ठ̄, leg. W.J. Pulawski [NMLS].

DIAGNOSIS. Holopyga lucens sp. n. belongs to the $H$. miranda group for the tarsal claws apically bifid and for body dorsally fully metallic red. Apparently species of this group from East Mediterranean countries (H. enslini Linsenmaier, 
1959) and Central Asia (H. lucens sp. n.) share mesosoma ventrally metallic red, whereas all the other species from West Mediterranean countries share black mesosoma (Holopyga miranda Abeille de Perrin, 1878; H. calida Linsenmaier, 1951; H.

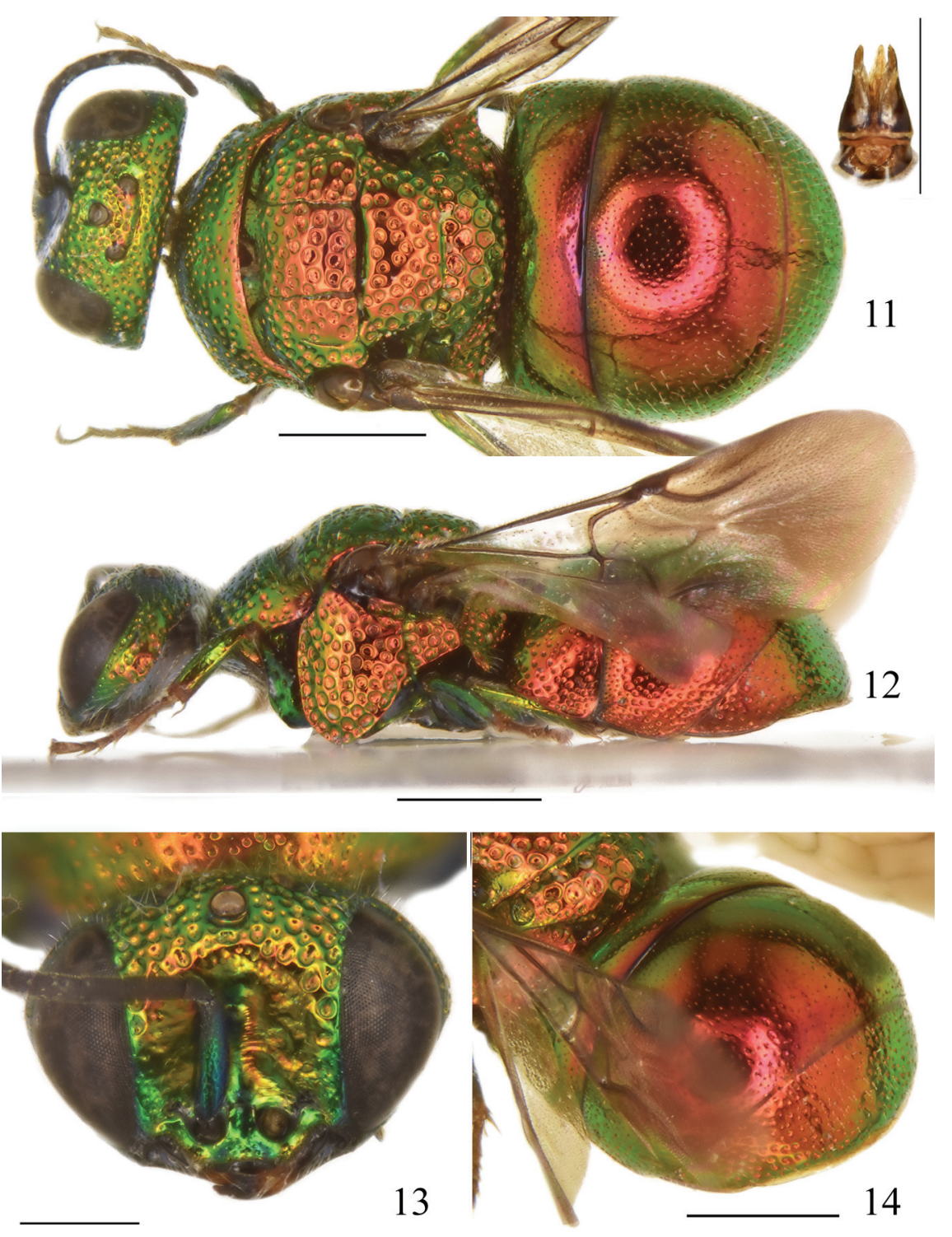

Figs 11-14. Holopyga lucens Rosa, sp. n., holotype $\delta^{\Uparrow}: 11$ - habitus, dorsal view; 12 habitus, lateral view; 13 - head, frontal view; $14-$ metasoma, dorso-lateral view. Scale bar $=$ $1.0 \mathrm{~mm}$. 
enslini Linsenmaier, 1959; H. mattheyi Linsenmaier, 1959; H. naefi Linsenmaier, 1959; H. tussaci Linsenmaier, 1999). H. lucens sp. n. is related to H. enslini, known from Palestine and Turkey (Linsenmaier 1959), yet it is separated for the shape of the head in dorsal view, as large as pronotum, and temples almost straight (vs. head larger than pronotum and temples posteriorly downwards directed in $H$. enslini); punctation of head and mesosoma scattered with polished and shining interstices (vs. punctation denser to confluent, without shining interstices); enlarged, carinate and ventrally rounded mesopleuron (vs. typically angulate); mesopleuron ventrally polished (vs. fully micropunctate); coxae, trochanters and femora shining metallic green (vs. blackish, almost without reflections).

DESCRIPTION. Body length $6.0-6.5 \mathrm{~mm}$. Fore wing length $4.0 \mathrm{~mm}$. Male. $\mathrm{OOL}=1.6 \mathrm{MOD} ; \mathrm{POL}=2.3 \mathrm{MOD} ; \mathrm{MS}=0.3 \mathrm{MOD}$; relative length of $\mathrm{P}: \mathrm{F} 1: \mathrm{F} 2: \mathrm{F} 3$ $=1.0: 1.4: 1.0: 0.8$.

Head. Frons with large to medium punctures, with polished and shining interstices, with sparse tiny dots on interstices; punctures on vertex and ocellar triangle smaller; posterior ocelli with polished lateral area; face shallowly hollowed; scapal basin polished and glabrous. Subantennal space less than 1.0 MOD. Clypeal apical margin bordered by narrow thickened rim (0.2 MOD). Mandibles bidentate. Ocellar triangle isosceles, with deep ocellar line connecting posterior ocelli.

Mesosoma. Pronotum with small, scattered punctures, with spare tiny punctures on interstices. Mesoscutum with large, yet shallow punctures, increasing in diameter towards base, with broad shining interstices. Scutellum with large, scattered punctures, with polished interstices. Notauli deep and complete; parapsidal lines incomplete, ending around half mesoscutum length. Mesopleuron exceptionally expanded ventrally, with curved profile (Fig. 12). Metapleuron enlarged, compared to other Holopyga. Metanotum with large (>1.0 MOD), foveate, irregular punctures, and narrow shining interstices. Propodeal teeth short, triangular, pointing slightly outwards. Forefemur ventrally carinate.

Metasoma. Metasomal terga with even and minute punctures, equally spaced dorsally, 2 - 4 PD apart; larger and almost contiguous laterally on first and second tergum. Apical margin of third tergum bent and bearing a narrow hyaline rim. Second sternum with scattered minute punctures, denser on third sternum.

Coloration. Body dorsally shining metallic red; ventrally with head and mesosoma red to coppery, metasoma black. Mandibles brown, medially testaceous. Scape green to coppery, pedicel and flagellum black. Wings smoky, darkened on margins. Tegulae non-metallic brown.

Vestiture. Head and mesosoma with sparse, whitish, short (1.0 MOD), and erected setae; head and mesosoma dorsally with whitish, short (less than 1.0 MOD long) and erect setae; metasoma with even shorter and sparser setae; coxae, trochanters, femora with long (2.0 MOD) and erect setae; metasoma with sparse long setae on second and third sternum.

Female. Unknown.

DISTRIBUTION. Turkmenistan, Uzbekistan.

ETYMOLOGY. The specific epithet lucens (adjective, invariable), from Latin, means shining, brilliant. It had already been chosen by Semenov and Nikol'skaya, because of the brilliant general appearance of this species. 
REMARKS. W. Linsenmaier, A.P. Semenov and M.N. Nikol'skaya recognized this outstanding species as not yet described and labelled it Holopyga noskiewiczi [NMLS] and H. lucens [ZIN] respectively; yet, in both cases, the description was never published.

\section{Hedychridium kilimniki Rosa, sp. n.} Figs 15-20

SPECIMENS EXAMINED. Holotype - + , Kazakhstan: Aktyubinskaya distr., Mugodzharj Mts., $15 \mathrm{~km} \mathrm{~N}$ Emba steppe, 11.VI 1985, leg. M. Nesterov [ZIN]. Paratype: 1 , same locality and collecting data [PRC].

DIAGNOSIS. Hedychridium kilimniki sp. n. belongs to the $H$. ardens group, $H$. femoratum subgroup, for non-metallic, yellowish tibiae and tarsi. It is separated from other species for its peculiar coloration, with head and mesosoma dorsally matt red to coppery, yet notauli, axillary trough and propodeum contrasting blue; metasoma metallic red with a large triangular black spot on second tergum (also face and metascutellum contrasting blue to green in H. femoratum Dahlbom, 1854, H. turanicum Semenov, 1954, H. elegantulum du Buysson, 1887). It is separated from the above species also for: notauli and other sutures distinctly deeper (Fig. 16); mesosoma punctation dense and irregular; punctation on second and third sternum dense and double, with a metallic basomedial spot on second sternum (sterna wholly black in the above species).

DESCRIPTION. Body length 4.0-5.0 mm. Fore wing length $2.8-3.5 \mathrm{~mm}$. Female. $\mathrm{OOL}=2.6 \mathrm{MOD} ; \mathrm{POL}=2.4 \mathrm{MOD} ; \mathrm{MS}=1.0 \mathrm{MOD}$; relative length of $\mathrm{P}: \mathrm{F} 1: \mathrm{F} 2: \mathrm{F} 3=1.0: 1.4: 0.7: 0.6$.

Head. Frons, vertex, face among scapal basin and eye with irregular, mediumsized punctures $(0.3 \mathrm{MOD})$, nearly contiguous, with small to tiny punctures on interstices; scapal basin transversely striate. Ocellar triangle isosceles; midocellus anteriorly, and posterior ocelli laterally sunken. Subantennal space about 1.0 MOD; clypeal margin with thickened rim (up to 1.0 MOD). Mandibles apically toothed; the details could not be examined, due to the impossibility to open the mandibles without risk to break them.

Mesosoma. Mesosoma with irregularly sized, contiguous to confluent punctation, generating a matt colour effect, similarly to the common H. coriaceum (Dahlbom, 1854). Notauli visible as rows of deep, elongate, blackish-blue foveae, contrasting with the rest of mesoscutal coloration. Axillary trough partly dark blue, also contrasting with red mesoscutellum and metascutellum. Metascutellum with foveatereticulate punctures, and irregular foveae. Propodeal teeth sharp, curved, pointing outwards and slightly backwards. Inner side of hindtibiae at apex with a large, subtriangular dark pit, extending over one third of the tibia length.

Metasoma. First and second tergum with even and minute punctures, evenly spaced dorsally, almost contiguous laterally. Apical margin of third tergum with narrow hyaline rim (0.5 MOD). Second and third sternum unusually deeply and densely punctate, with double punctures. 


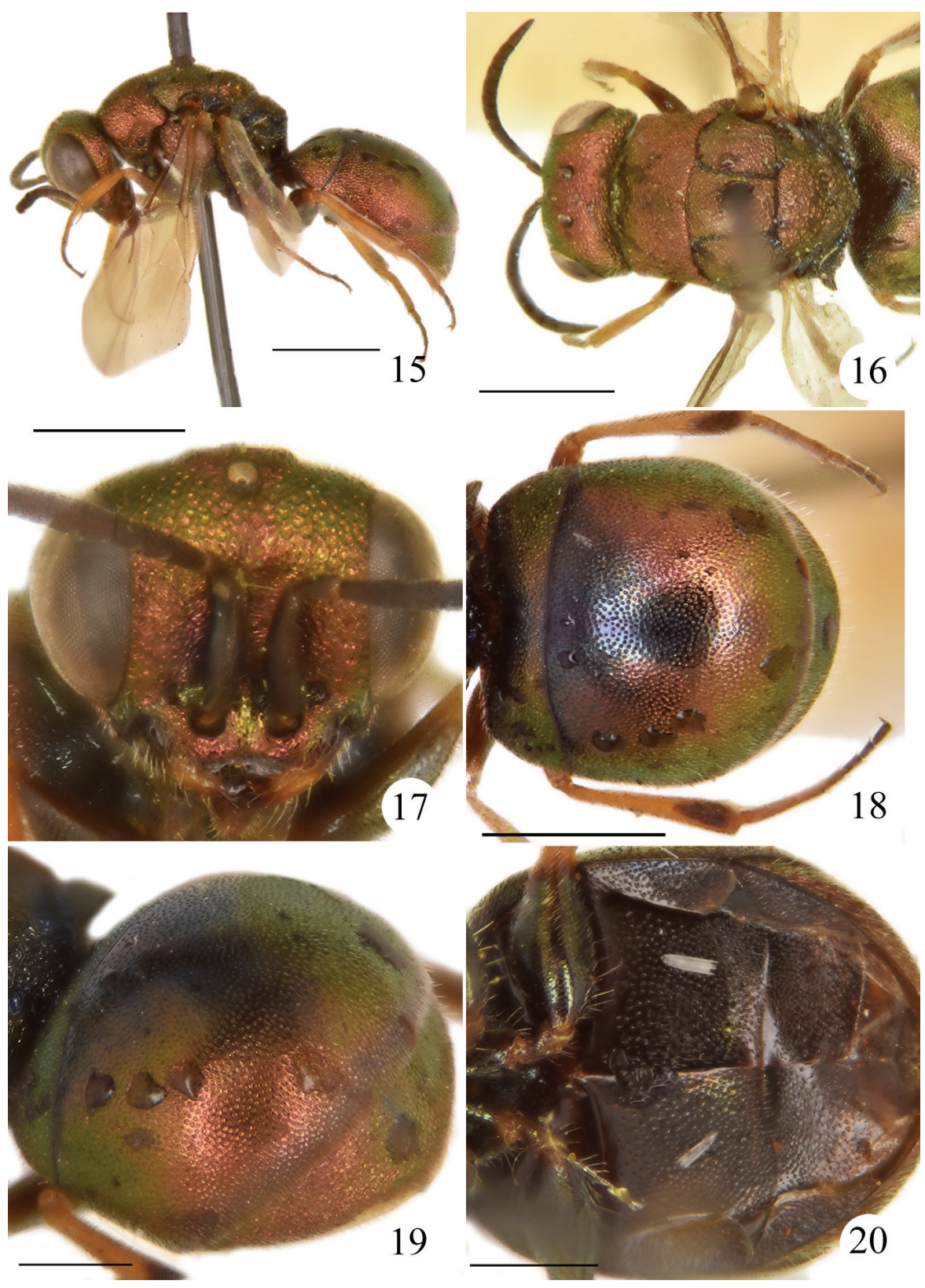

Figs 15-20. Hedychridium kilimniki Rosa, sp. n., holotype $\delta^{\lambda}: 15$ - habitus, lateral view; 16 - mesosoma, dorsal view; 17 - head, frontal view; 18 - metasoma, dorsal view; 19 metasoma, dorso-lateral view; $20-$ metasoma, ventral view. Scale bar $=1.0 \mathrm{~mm}$. 
Coloration. Body metallic red to coppery; dark blue to blackish on notauli, axillary trough, and propodeum. Metasoma metallic red with a large triangular black spot on second tergum; ventrally black, with a triangular coppery spot on second sternum. Mandibles brown, medially testaceous. Scape coppery, pedicel and flagellum dark brown. Legs with coxae and outer side of femora coppery, the rest yellowish testaceous. Wings slightly smoky, without darkened margins.

Vestiture. Body dorsally covered by dense, whitish, short setae (less than 1 MOD); ventrally, on lower face and femora with long setae (> 1 MOD).

Male. Unknown.

DISTRIBUTION. Kazakhstan.

ETYMOLOGY. The specific epithet kilimniki (masculine name in genitive case) is named after A.N. Kilimnik (Odessa, Ukraine), who firstly recognized this species as still undescribed.

Hedychridium fadeevi Rosa, sp. n.

Figs 21-24

SPECIMENS EXAMINED. Holotype - + , Kazakhstan: Almatinskaja oblast, env. Akzahr, 397 m, 4452'49'’N 7553'11' 'E, 26.V 2015, leg. K.I. Fadeev [ZIN]. Paratype: 1 , same data of holotype [PRC].

DIAGNOSIS. Hedychridium fadeevi sp. n. is herewith included into the $H$. ardens species group, despite of some peculiar features, namely the unusually elongate, slender mandibles and tarsi, particularly the last tarsomere. Its bicolored body coloration, with head and mesosoma green and metasoma red, is found in only few known Central Asian Hedychridium species, belonging to H. flos, H. roseum, and $H$. ardens species groups. $H$. fadeevi cannot be included in the $H$. flos group, because of the unmodified face and fore femur (face with sharp, M-shaped transverse frontal carina; fore femur ventrally carinate and angulate in $H$. flos group); nor it can be included in the $H$. roseum group, because of the elongate tarsomeres (hind tarsomeres robust, stocky, the second shorter than the third in H. roseum group). Within the $H$. ardens group, only $H$. alpestre Semenov, 1954, H. trossulus Semenov, 1954 and $H$. sibiricum Rosa, 2017 share a similar coloration; however $H$. alpestre and $H$. trossulus can be easily separate for scapal basin transversely striate (finely punctate in $H$. fadeevi sp. n.), and mesosoma punctures scattered (closer to confluent in $H$. fadeevi sp. n.). Finally, $H$. fadeevi sp. n. is separated from $H$. sibiricum for the elongate and falciform mandibulae, F1 short $(1 / \mathrm{w}=2)$, mid and hindfemura nonmetallic, testaceous (unmodified and bidentate mandibulae, F1 long $(1 / \mathrm{w}=3)$, femura metallic in $H$. sibiricum).

DESCRIPTION. Body length $6.4 \mathrm{~mm}$. Fore wing length $4.0 \mathrm{~mm}$. Female. OOL $=2.1 \mathrm{MOD} ; \mathrm{POL}=2.0 \mathrm{MOD} ; \mathrm{MS}=0.5 \mathrm{MOD}$; relative length of $\mathrm{P}: \mathrm{F} 1: \mathrm{F} 2: \mathrm{F} 3=$ 1.0:1.0:0.9:0.8

Head. Frons and vertex with dense and small punctures, nearly contiguous on vertex, with tiny punctures on interstices; polished on two areas laterally to posterior ocelli; face flat, all over with dense tiny punctures, medially scattered. Subantennal 


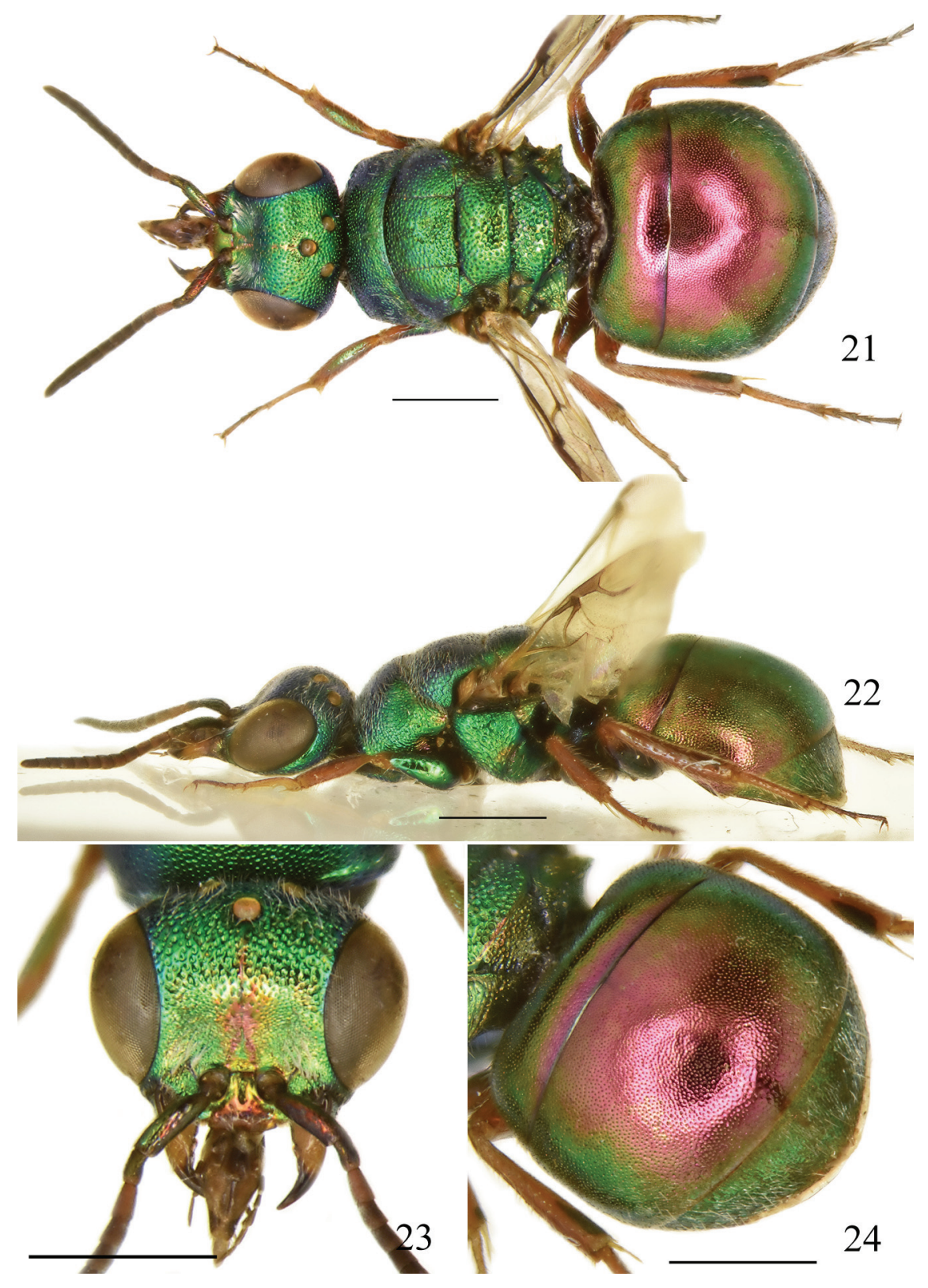

Figs 21-24. Hedychridium fadeevi Rosa, sp. n., holotype $\bigcirc: 21$ - habitus, dorsal view; 22 - habitus, lateral view; 23 - head, frontal view; 24 - metasoma, dorso-lateral view. Scale bar $=1.0 \mathrm{~mm}$. 
space less than 1.0 MOD. Clypeal apical margin bordered by large thickened rim (0.8 MOD). Mandibles distinctly elongate and sickle-like, without inner tooth. Ocellar triangle isosceles; midocellus anteriorly, and posterior ocelli laterally sunken.

Mesosoma. Mesosoma with dense, fine to moderate punctures, contiguous to confluent on mesoscutum. Scutellum with double punctures, with shallow tiny and small, scattered punctures (1 PD), with polished interstices. Notauli and parapsidal lines narrow and complete. Metascutellum with dense, deep, foveate, irregular punctures, larger than those on mesoscutellum. Propodeal teeth short, triangular, and pointing outwards; propodeum transversely striate before propodeal teeth; median propodeal area covered by dense, tiny punctures. Mid-, hindtibia and femora distal joints ferruginous; midtibia with a small, round dark pit at base of inner side; hindtibia with enlarged dark pit, as long as one third of entire length. Last tarsomeres distinctly elongate $(1 / \mathrm{w}=6)$; tarsal claws elongate (as long as $3 / 5$ of last tarsomere); tibia and tarsomere bear long and spiniform bristles.

Metasoma. First and second tergum with even and minute punctures, dorsally equally spaced, laterally almost contiguous, as well as on the whole third tergum. Apical margin of third tergum with hyaline rim (0.5 MOD). Second and third sternum with scattered double punctures (1-4 PD apart).

Coloration. Head and mesosoma wholly metallic green; metasoma dorsally pinkish-red, ventrally black with a green to purplish large spot on second sternum. Mandibles brown, basally metallic green, in the middle testaceous, apically dark brown. Scape and pedicel green to coppery, flagellum brown, with F1 light brown. Wings almost hyaline. Foretibia slightly metallic green, mid-, hindtibia and tarsi ferruginous.

Vestiture. Face laterally and basally with silvery appressed setae; head and mesosoma dorsally with whitish, short (1.0 MOD long), and erect setae; metasoma laterally and on third tergum with longer, appressed setae, and sparse, erect shorter setae; coxae, trochanters and femora with long and erect bristles.

Male. Unknown.

DISTRIBUTION. Kazakhstan.

ETYMOLOGY. The specific epithet fadeevi (masculine name in genitive case) is named after K.I. Fadeev (Russia), who collected the type specimens.

\section{Tribe Chrysidini}

\section{Chrysis leleji Rosa, sp. n.} Figs 25-28

SPECIMENS EXAMINED. Holotype - + , Russia: Altai Rep., Tashanta, desert steppe, 14.VI 1977, V. Richter [ZIN].

DIAGNOSIS. The actual placement of Chrysis leleji sp. n. is highly uncertain, indeed unpredictable without male examination. At first sight it could even be placed into the genus Chrysura, Ch. radians group, for toothed mandibles, general habitus, and shape of the head, enlarged with convergent malar spaces. However, the scapal 
basin transversely wrinkled is a diagnostic feature of Chrysis. Male flagellomeres and genital capsule may help to clarify the placement of this species. C. leleji shows the typical habitus of Alpine species: flattened body; shallow and sparse punctation; long erect setae on body and darkened coloration (Rosa et al. 2017b). A vaguely similar habitus is shared only with another central Asian species found at high altitudes, Chrysis pamirica Tarbinsky, 2002 (C. rufitarsis group), from Pamir (3730 m),

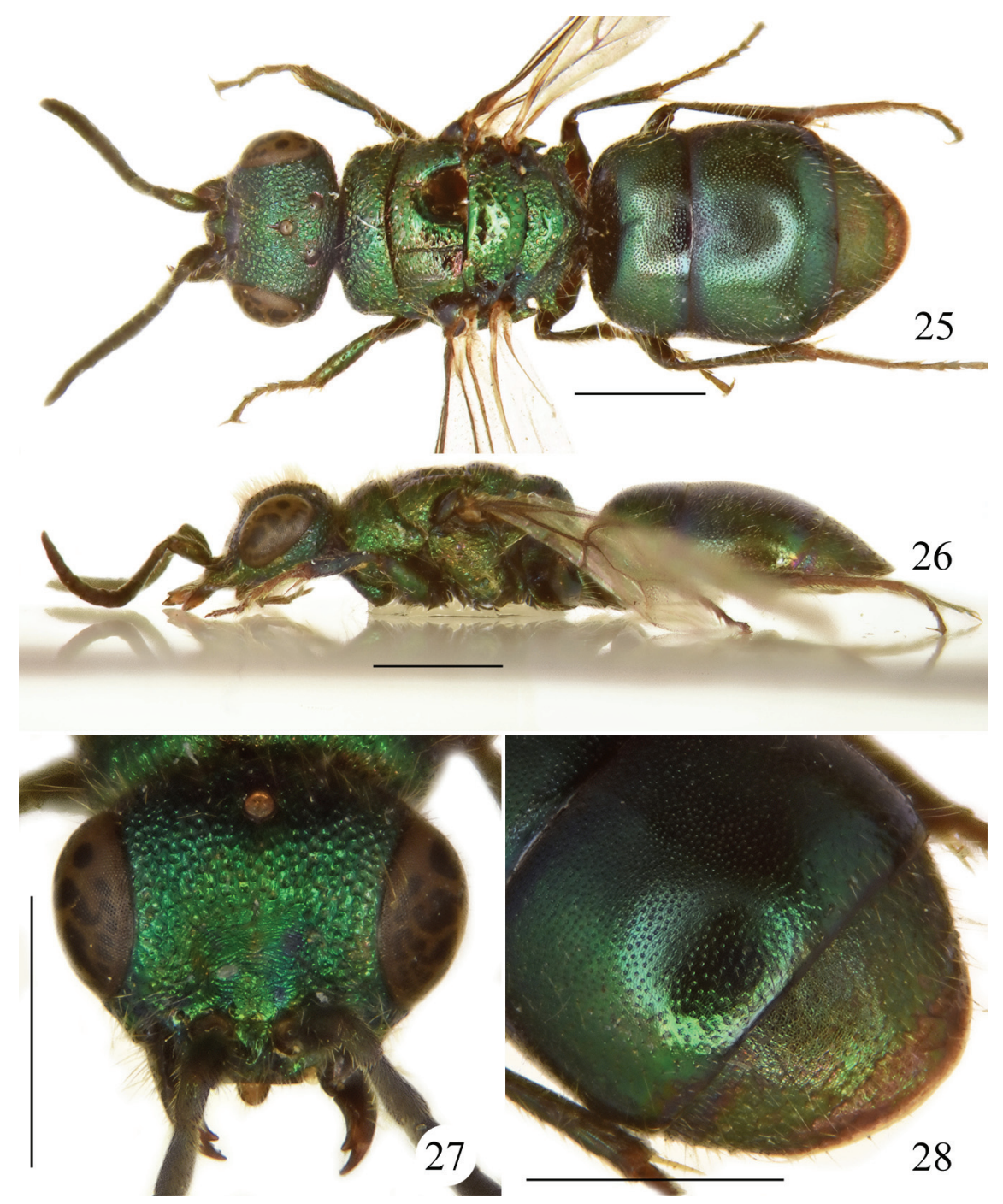

Figs 25-28. Chrysis leleji Rosa, sp. n., holotype $9: 25$ - habitus, dorsal view; 26 - habitus, lateral view; 27 - head, frontal view; 28 - metasoma, dorso-lateral view. Scale bar $=1.0 \mathrm{~mm}$. 
easy recognizable for undulate, angulated apical margin of third tergite. C. leleji sp. $\mathbf{n}$. is immediately recognizable for darkened greenish body coloration; scapal basin medially hollowed, transversely striate; punctation on mesosoma scattered, with small punctures; large and polished interstices on mesoscutellum; punctation on metasoma with tiny, even punctures and interstices among punctures with a unique reticulate microsculpture. Moreover, noteworthy are: the flattened metasoma; the second metasomal tergum widen on the posterior half; the inner tooth of the mandible, positioned on dorsal side (Figs 26, 27).

DESCRIPTION. Body length $5.5 \mathrm{~mm}$. Fore wing length $4.0 \mathrm{~mm}$. Female. OOL $=2.8 \mathrm{MOD} ; \mathrm{POL}=2.8 \mathrm{MOD} ; \mathrm{MS}=1.5 \mathrm{MOD}$; relative length of P:F1:F2:F3 = 1.0:1.4:0.7:0.7

Head. In full face view, length $1.1 \mathrm{~mm}$, width $1.5 \mathrm{~mm}$. Apex of clypeus medially straight; TFC faint; face almost flat, scapal basin medially hollowed and transversely striate; frons, vertex, area between compound eye and scapal basin with moderately large, deep, dense to continuous punctures. Malar space 1.4 MOD, shorter than F1. Mandibles with subapical internal tooth, dorsally placed. Subantennal distance about 1.0 MOD. Ocelli not lidded.

Mesosoma. Length $1.9 \mathrm{~mm}$; width (PPW) $1.3 \mathrm{~mm}$. Pronotum slightly depressed anteromedially, without defined anteromedian groove; punctation irregular, with shallow, uneven punctures, small to medium-sized, partly contiguous, with polished interstices, somewhere with tiny punctures. Punctures on mesoscutum small, shallow and scattered, with large polished areas; interstices transversely striate, well visible on lateral areas; notauli and parapsidal lines complete. Mesoscutellum with mediumsized, scattered punctures, 1-3 PD apart, denser towards axillary trough. Metanotum with denser punctures, yet scattered medially with large polished interstices. Mesopleuron with shallow irregular punctures; episternal sulcus on upper part formed by enlarged foveae. Propodeal teeth divergent, pointing backwards.

Metasoma. Length $2.4 \mathrm{~mm}$. Punctation on first tergum with small, dense (about $1 \mathrm{PD}$ apart), even punctures; posterior margin with a narrow (about 1.0 MOD), darker and impunctate stripe; microreticulation on interstices faint to ill defined. Second tergum with similar puntaction, sparser towards posterior and lateral margins, with reticulate microsculpture on interstices; with scattered, small punctures and impunctate stripe on posterior margin. Third tergum subovoid, with apical margin evenly arcuate, with no lateral angles nor medial notch; narrow hyaline rim at apex; pit row ill-defined, with shallow and small pits, only a little larger and deeper than other punctures; post pit row area medially enlarged, as long as 1.5 MOD; punctation on third tergum similar to second one, with reticulate microsculpture on interstices. Black spots on second sternum large, ovoid, medially separated by $1.0 \mathrm{MOD}$; sterna with reticulate microsculpture.

Internal segments. The internal metasomal segments forming the ovipositor tube are shortened, with short chitinous forks and broad, enlarged membranes.

Coloration. Body entirely metallic green; mesosoma with coppery or olive reflections; metasoma darker to bluish. Body ventrally dark green. Mandibles brown, with metallic green reflections at base, medially testaceous. Scape and pedicel metallic green, flagellum black. Tibiae dark with greenish reflections. Tegulae metallic. Wings hyaline. Body colour does not change in while rehydrating the specimen. 
Vestiture. Frons, vertex, and mesosoma covered by dense, long (2.0 MOD), erect, brownish setae. Metasoma laterally, posteriorly and ventrally with long brownish setae; coxae and femora covered by long bristles.

Male. Unknown.

DISTRIBUTION. Russian Altai.

ETYMOLOGY. The specific epithet leleji (masculine name in genitive case) is named after A.S. Lelej (Vladivostok, Russia), who encouraged me to study Russian Chrysididae in the last years.

\section{Chrysis kazenasi Rosa, sp. n.} Figs 29-32

SPECIMENS EXAMINED. Holotype - $\hat{\jmath}$, Kazakhstan: $50 \mathrm{~km}$ SW of vill. Bairkum, Kyzyl-kum, 14.V 1992, leg. V. Kazenas [ZIN]. Paratypes: same locality of holotype: 9.V 1992, 1ð, 14.V 1992, $2 \widehat{\jmath}$ [PRC, ZIN]; $50 \mathrm{~km}$ W of Koksu, Kyzylkum desert, 8-10.V 1992, 3ðे, leg. V. Kazenas [PRC, ZIN]; $40 \mathrm{~km} \mathrm{SW}$ of vill. Bairkum, Kyzyl-kum, 14.V 1992, 19, leg. V. Kazenas [ZIN].

DIAGNOSIS. Chrysis kazenasi sp. n. belongs to the C. curta species group, for shape of genital capsule (see the forthcoming issue); TFC faint; unmodified male flagellomeres; face with punctation contrasting with those of vertex; edentate apical margin of the third metasomal tergum; the latter short and broad, slightly emarginate medially; black spots on second metasomal sternum large, subsquare, and medially close. C. kazenasi sp. n. is similar to C. batyamensis Linsenmaier, 1969, sharing similar habitus and coloration; yet $C$. kazenasi sp. n. is recognizable for the short malar space, about 1 MOD (vs. 3 MOD in C. batyamensis); punctation on mesosoma irregular; punctation on metasoma dense on anterior half, scattered with wide shining interstices on posterior half (vs. double punctures all over metasoma); pit row almost faint, with very narrow post pit row area (vs. large and round pits; post pit row area normally developed).

DESCRIPTION. Body length $5.9 \mathrm{~mm}$. Fore wing length $3.5 \mathrm{~mm}$. Male. OOL $=$ 2.0 MOD; POL $=1.7 \mathrm{MOD} ; \mathrm{MS}=1.0 \mathrm{MOD}$; relative length of P:F1:F2:F3 = 1.0:1.4:1.0:0.8

Head. In full face view, length $1.3 \mathrm{~mm}$, width $1.5 \mathrm{~mm}$. Apex of clypeus slightly emarginate; TFC faint; scapal basin slightly hollowed and fully, densely punctate with minute punctures, covered with silvery, appressed setae; frons and vertex with small to medium-sized, contiguous punctures. Malar space 1.0 MOD, shorter than F1 (2.0 MOD). Mandibles with subapical, small tooth. Subantennal distance about 1.2 MOD. Ocelli not lidded. Genal carina fully developed to mandibular joint; malar spaces finely punctured.

Mesosoma. Length $2.0 \mathrm{~mm}$; width (PPW) $1.5 \mathrm{~mm}$. Pronotum with weak anteromedian groove, reaching to mid-length; punctation irregular, with shallow, small to medium-sized punctures, partly contiguous or even confluent; interstices narrow and polished. Punctation similar on mesoscutum; with larger, scattered punctures on mesoscutellum. Metanotum with irregular, denser punctures, in some paratypes with anteromedian pit. Mesopleuron with small, irregular punctures, without visible episternal sulcus. Propodeal teeth subparallel, pointing backwards. 
Metasoma. Length $2.5 \mathrm{~mm}$. First tergum distinctly elongate, as long as $2 / 3$ of the second tergum length; punctation with small, tiny, dense, and even punctures; on second sternum medially smaller, posteriorly larger and sparser; third tergum with post pit row area narrow; pits of the pit row small, shallow, a little larger than other punctures. Black spots on second sternum large, squarish, medially almost fused.

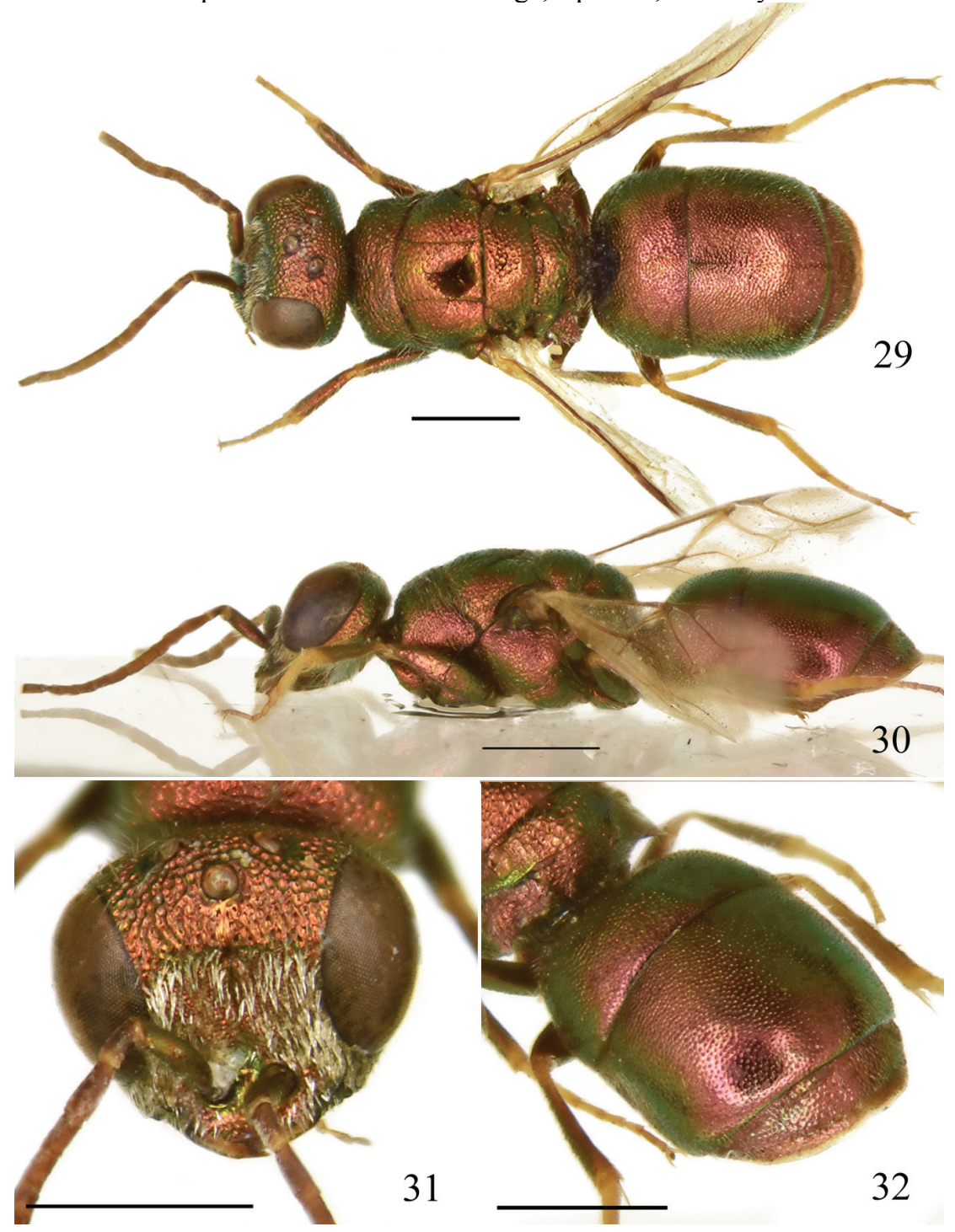

Figs 29-32. Chrysis kazenasi Rosa, sp. n., holotype $\bigcirc$ : 29 - habitus, dorsal view; $30-$ habitus, lateral view; 31 - head, frontal view; 32 - metasoma, dorso-lateral view. Scale bar $=$ $1.0 \mathrm{~mm}$. 
Coloration. Body entirely red, in some specimens more coppery to greenish. Mandibles brown, with metallic green reflections at base and medially testaceous. Scape coppery, pedicel and flagellum testaceous. Legs metallic red, testaceous on joints and tarsi. Tegulae metallic red. Wings hyaline with light brown nervures.

Vestiture. Frons, vertex and mesosoma with short (1.0 MOD), erect, whitish setae.

Female. Similar to male, yet inner tooth on mandible almost smooth (likely worn out); flagellum black; anteromedian pit on scutellum larger and deeper; setae on mid- and hindtibia longer and perpendicular.

DISTRIBUTION. Kazakstan.

ETYMOLOGY. The specific epithet kazenasi (masculine name in genitive case) is dedicated to V.L. Kazenas (Almaty, Kazakstan), who collected most of the chrysidids studied in this article and kindly donated to ZIN.

Chrysis gertiana Rosa, sp. n.

Figs 33-36

SPECIMENS EXAMINED. Holotype - $q$, Iran: Elburs, $50 \mathrm{~km}$ S Chalus, 2800m, 26.VII 1977, leg. J. Gusenleitner, GBIF Chr00018953 [NMLS]. Paratypes: Iran: 1 , , same collecting data of holotype [PRC]; Turkmenistan: $5 \mathrm{~km} N$ of KaraKala, Tarkhaj canyon, 2.V 1991, 1 9 , leg. V. Kazenas [ZIN].

DIAGNOSIS. Chrysis gertiana sp. n. is a remarkable species, whose insertion in a species group without examination of the male is uncertain; I here consider its placement as provisional. For the edentate shape of the apical margin it may be related to $C$. curta, C. millenaris, $C$. phryne or $C$. rubricata species groups. Nevertheless, from all these groups it is separated by the short malar spaces and the ill-defined black spots on second metasomal tergum; from the first two groups also by well outlined TFC and large dimensions. It is recognizable for the coloration and the large and triangular mesoscutal antero-lateral corners over mesoscutal trough.

DESCRIPTION. Body length $6.9 \mathrm{~mm}$. Fore wing length $4.5 \mathrm{~mm}$. Female. OOL $=1.9 \mathrm{MOD} ; \mathrm{POL}=1.9 \mathrm{MOD} ; \mathrm{MS}=1.0 \mathrm{MOD}$; relative length of $\mathrm{P}: \mathrm{F} 1: \mathrm{F} 2: \mathrm{F} 3=1.0$ : $1.5: 0.8: 0.7$

Head. In full face view, length $1.6 \mathrm{~mm}$, width $2.0 \mathrm{~mm}$. Apex of clypeus medially markedly notched at obtuse angle, bordered by a thick rim (0.5 MOD); TFC wellmarked, M-shaped; scapal basin hollowed, medially transversely striate, laterally with dense, tiny punctures, covered by short, appressed, silvery setae. Malar space 1.0 MOD, as long as 1/5 of F1. Genal carina fully developed up to mandibular joint. Subantennal distance about 1 MOD. Ocelli not lidded.

Mesosoma. Length $2.6 \mathrm{~mm}$; width (PPW) $1.8 \mathrm{~mm}$. Pronotum anteromedially with deep groove exceeding half pronotal length; punctation double, with small and medium-sized punctures (0.4 MOD). Mesoscutum with similar punctures, denser and subreticulate; notauli complete and parapsidal lines incomplete, hardly visible. Mesoscutellum with larger punctures (up to 0.5 MOD), with shining interstices and small to very small punctures among larger punctures; mesoscutal antero-lateral corners over axillary trough large and triangular. Metascutellum with denser and larger punctures. Mesopleuron with dense and irregular punctures; episternal sulcus 
hardly recognizable only above for 3-4 aligned larger and foveate punctures. Propodeal teeth diverging and pointing backwards.

Metasoma. Length $3.0 \mathrm{~mm}$. Punctation on first tergum with small and scattered punctures, denser along posterior margin, with copious small punctures on interstices. Second tergum with smaller, deep, geminate punctures, transversally subcontiguous on the anterior half, smaller and scattered on the posterior one, in the middle of the latter almost impunctate, only with minute dots; laterally with tiny punctures on interstices.

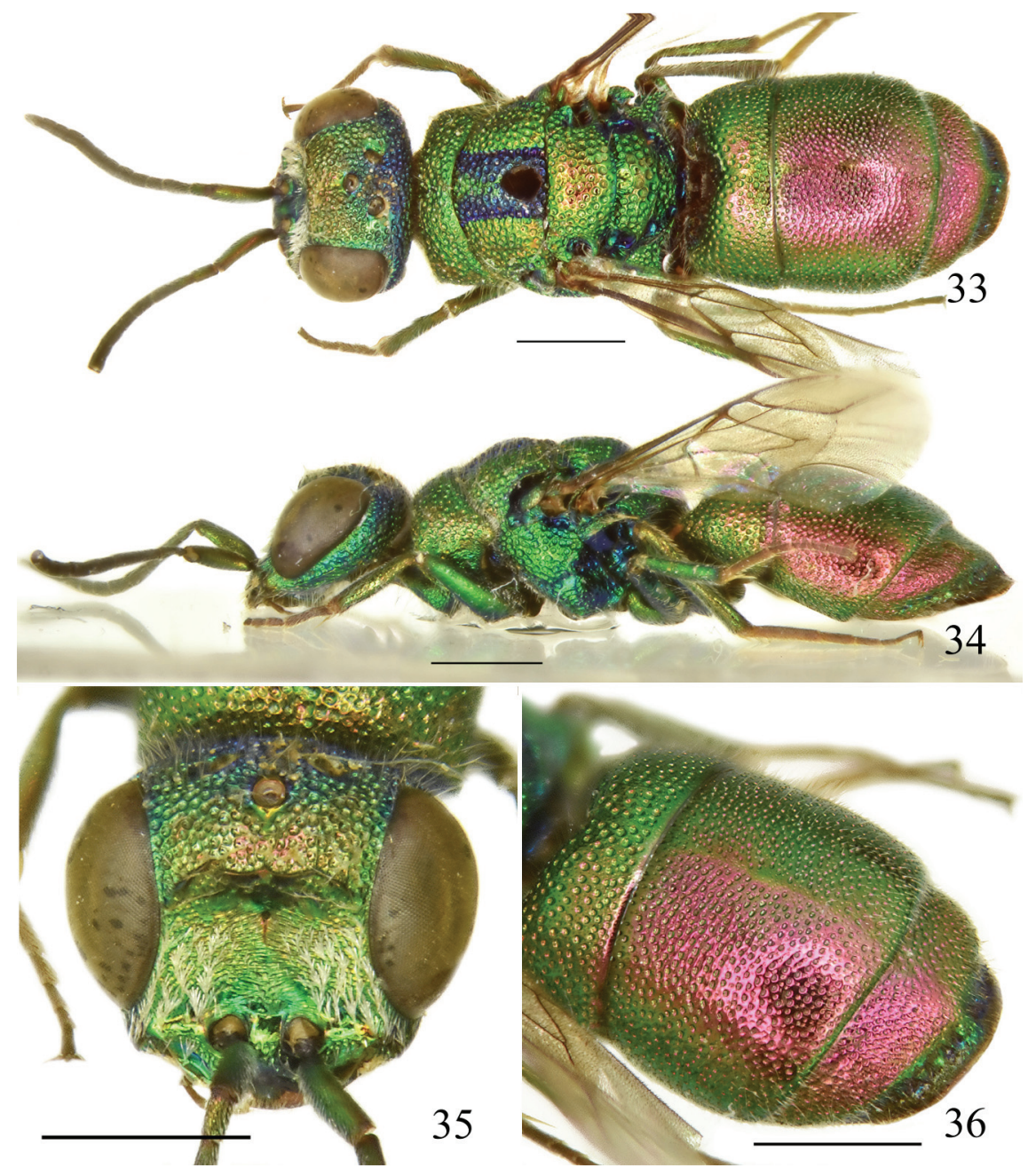

Figs 33-36. Chrysis gertiana Rosa, sp. n., paratype + from Turkmenistan: 33 - habitus, dorsal view; 34 - habitus, lateral view; 35 - head, frontal view; 36 - metasoma, dorso-lateral view. Scale bar $=1.0 \mathrm{~mm}$ 
Third tergum with irregular punctation; apical margin smooth, edentate; pits of the pit row deep, elongate; post pit row area narrow. Black spots on the second sternum ill-defined and small.

Coloration. Body golden-green; bluish on ocelli area and occiput, median lobe of mesoscutum, sutures and axillary trough, and posterior edge of third metasomal tergum; metasoma pinky red to coppery, first tergum distinctly more green. Body ventrally dark green. Mandibles brown, medially lighter, with metallic green reflections at base. Scape, pedicel and F1 basally metallic green, flagellum black. Legs green with brown tarsi. Tegulae metallic green. Wings light brownish.

Vestiture. Face laterally covered by short, appressed, silvery setae; frons, vertex, mesosoma and metasoma dorsally covered by short (1.0 MOD), erect, whitish setae. Body ventrally with longer setae.

Male. Unknown.

DISTRIBUTION. Iran, Turkmenistan.

ETYMOLOGY. The species is named after the late Gerti (Gertrude) Heim (Luzern, Switzerland), who friendly supported my studies on Chrysididae for several years, while studying the Linsenmaier collection.

Chrysis fastigiata Rosa, sp. n.

Figs $37-40$

SPECIMENS EXAMINED. Holotype - , Kazakhstan: $40 \mathrm{~km} \mathrm{SW}$ vill. Bairkum, Kyzyl-kum, 15.V 1992, leg. V. Kazenas [ZIN].

DIAGNOSIS. Chrysis fastigiata sp. n. belongs to the $C$. elegans species group for cylindrical, elongate habitus; TFC faint; face broadened below, subparallel and short malar space; apex of T3 edentate; pubescence short and whitish; forewing radial cell closed. It can be easily separated from other species by the unique shape of the third tergite apical margin, in posterior view, forming a widely open angle, somewhat roof-shaped, similar to Chrysura baiocchii Rosa, 2013, yet with unmodified internal urites; and also for the double and coarse punctation of the last metasomal tergum; finally for body colour, with head and mesosoma green and metasoma red to violet. Only C. transcaspica Mocsáry, 1889 shares a similar coloration, but the latter is immediately recognizable for its habitus, similar to $C$. elegans Lepeletier, 1806; larger size, even exceeding $10 \mathrm{~mm}$; in dorsal view, head broadened behind compound eyes; posterior margin of T3 bent downwards.

DESCRIPTION. Body length $7.0 \mathrm{~mm}$. Fore wing length $4.8 \mathrm{~mm}$. Female. OOL $=1.3 \mathrm{MOD} ; \mathrm{POL}=2.1 \mathrm{MOD} ; \mathrm{MS}=1.0 \mathrm{MOD}$; relative length of $\mathrm{P}: \mathrm{F} 1: \mathrm{F} 2: \mathrm{F} 3=$ 1.0:1.5: $1.0: 0.8$.

Head. In full face view, length $1.7 \mathrm{~mm}$, width $1.8 \mathrm{~mm}$. Apex of clypeus medially straight; TFC faint, yet with prominent brow, overhanging sunken scapal basin; the latter hollowed, medially polished with scattered small punctures, laterally densely, minutely punctured; brow, in frontal view, with large, subcontiguous to confluent punctures; vertex with small, reticulate punctures, and impunctate area laterally to posterior ocelli. Malar space 1.0 MOD, shorter than F1 and subparallel. Subantennal distance less than 1.0 MOD. Subgenal carina almost complete, extending from middle gena to mandible joint. 


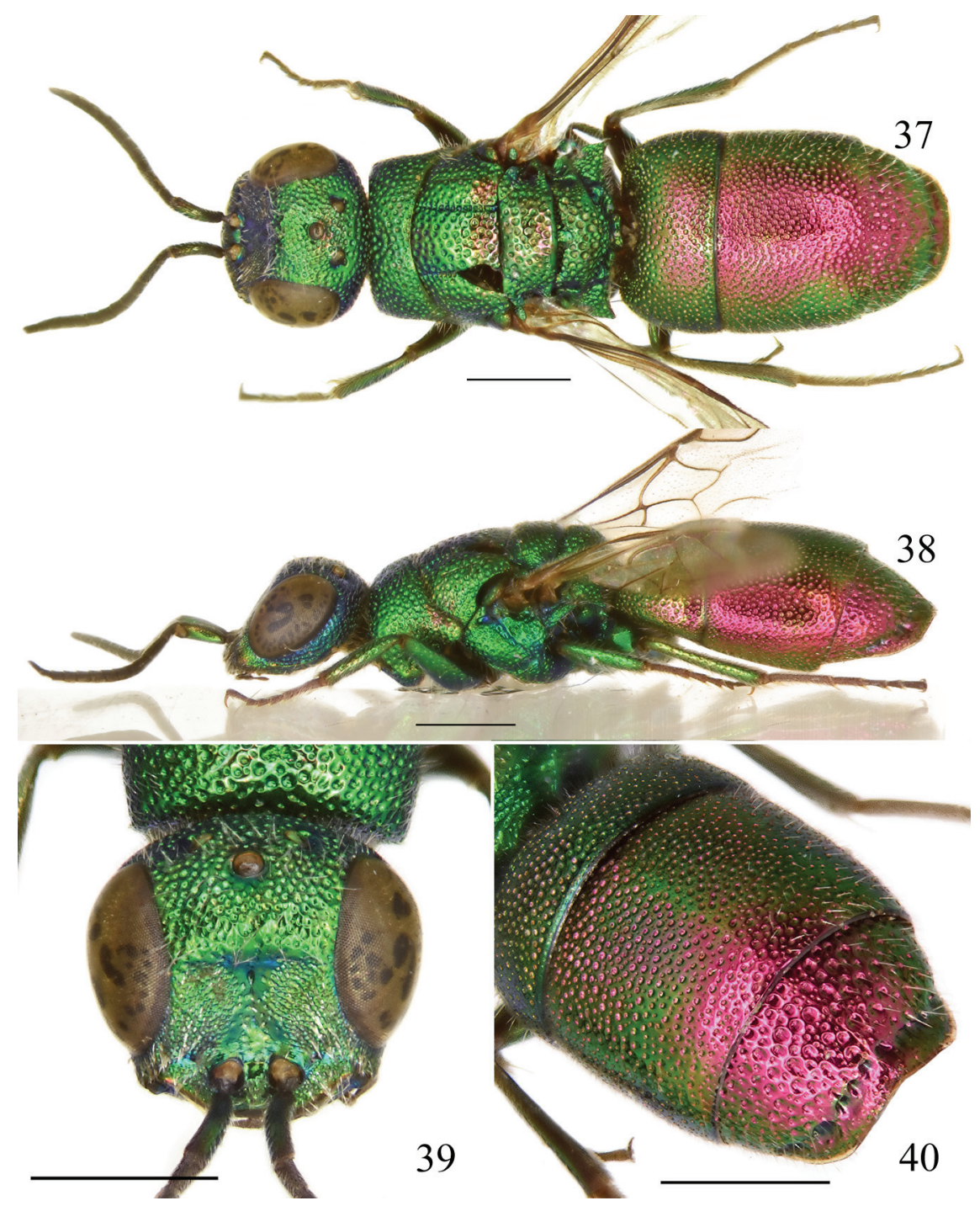

Figs 37-40. Chrysis fastigiata Rosa, sp. n., holotype ㅇ. 37 - habitus, dorsal view; $38-$ habitus, lateral view; 39 - head, frontal view; 40 - metasoma, dorso-lateral view. Scale bar = $1.0 \mathrm{~mm}$.

Mesosoma. Length $2.5 \mathrm{~mm}$; width (PPW) $1.8 \mathrm{~mm}$. Pronotum anteromedially slightly depressed, without distinct anteromedian groove; punctation double, subreticulate, with medium-sized punctures (about $0.3 \mathrm{MOD}$ ) and small punctures $(0.1$ MOD) on interstices; punctures laterally denser. Mesoscutum with medium-sized punctures, larger towards mesoscutellum, among notauli, with polished and shining 
interstices, 1 PD apart; notauli and parapsidal lines complete; notauli with deep, round pits, decreasing from posterior to anterior margin. Mesoscutellum with double punctation and polished interstices; punctures denser towards axillary trough. Punctation on metanotum irregular, subreticulate, with punctures of different size and large anteromedian fovea. Mesopleuron with shallow, sparse punctures; episternal sulcus formed by deep, subrectangular foveae. Propodeal teeth triangular, markedly enlarged, divergent and pointing backwards.

Metasoma. Length $3.2 \mathrm{~mm}$. Punctation on first and second tergum with medium-sized, subreticulate punctures, about 1 PD apart, with minute dots or small punctures on interstices. Third tergum with strongly contrasting, irregular, coarse punctation, consisting of large, deep foveate punctures, and small to minute punctures in the interstices, with distinct longitudinal median carina; apical margin distinctly dorso-ventrally angulate in the middle, without lateral angles and with a narrow apical hyaline rim; pits of the pit row deep, round, and separate, a little larger than larger punctures on the tergum; post pit row area with minute punctures; second sternum with large black spots, medially separated by a thin line and covering about $2 / 3$ of sternum length.

Coloration. Head and mesosoma green; dorsally with rosy reflections, more obvious on mesoscutum close to mesoscutellum and on the latter. Metasoma red to violet, with greenish reflections, ventrally green, with coppery reflections. Mandibles brown, with green reflections at base. Scape metallic green, pedicel and flagellum black. Legs green, tarsi brown. Tegulae metallic green. Wings hyaline, with brown veins.

Vestiture. Frons, vertex and mesosoma covered by sparse, whitish, long (1.0 MOD), and erect setae. Metasoma laterally, posteriorly and ventrally with long whitish setae.

Male. Unknown.

DISTRIBUTION. Kazakhstan.

ETYMOLOGY. The specific epithet fastigiata (adjective, feminine), from the Latin fastigium (= roof), refers to the angulate roof-shaped third metasomal tergum, seen in posterior view.

Chrysis diadema Rosa, sp. n.

Figs 41-44

SPECIMENS EXAMINED. Holotype - $\hat{\jmath}$, Turkmenistan: st. Akhcha-Kujma, 6.VII 1934, leg. V. Popov [ZIN].

DIAGNOSIS. Chrysis diadema sp. n. belongs to the C. pulchella species group for its stocky habitus; TFC strongly raised, M-like; F1 elongate (1/w 5.5); second metasomal tergum with fairly developed medial ridge; black spots on the second metasomal sternum large, quadrangular; male genital capsule with slender gonocoxae. It can be easily separated from all other species of this group for some unique features, namely: shape of apical margin of the third metasomal tergum, with inner blunt teeth replaced by broadly rounded undulations, separated by a slightly angulate medial 
space; TFC of unique shape, raised as a crown and medially bilobed; unusually elongate propodeal teeth; deep, foveate metasomal punctation, scattered on the second half of second tergum; distinctive genital capsule.

DESCRIPTION. Body length $7.0 \mathrm{~mm}$. Fore wing length $4.0 \mathrm{~mm}$. Male. $\mathrm{OOL}=$ 1.5 MOD; POL $=1.9 \mathrm{MOD} ; \mathrm{MS}=0.9 \mathrm{MOD}$; relative length of P:F1:F2:F3 = 1.0:2.0:1.1:0.9.

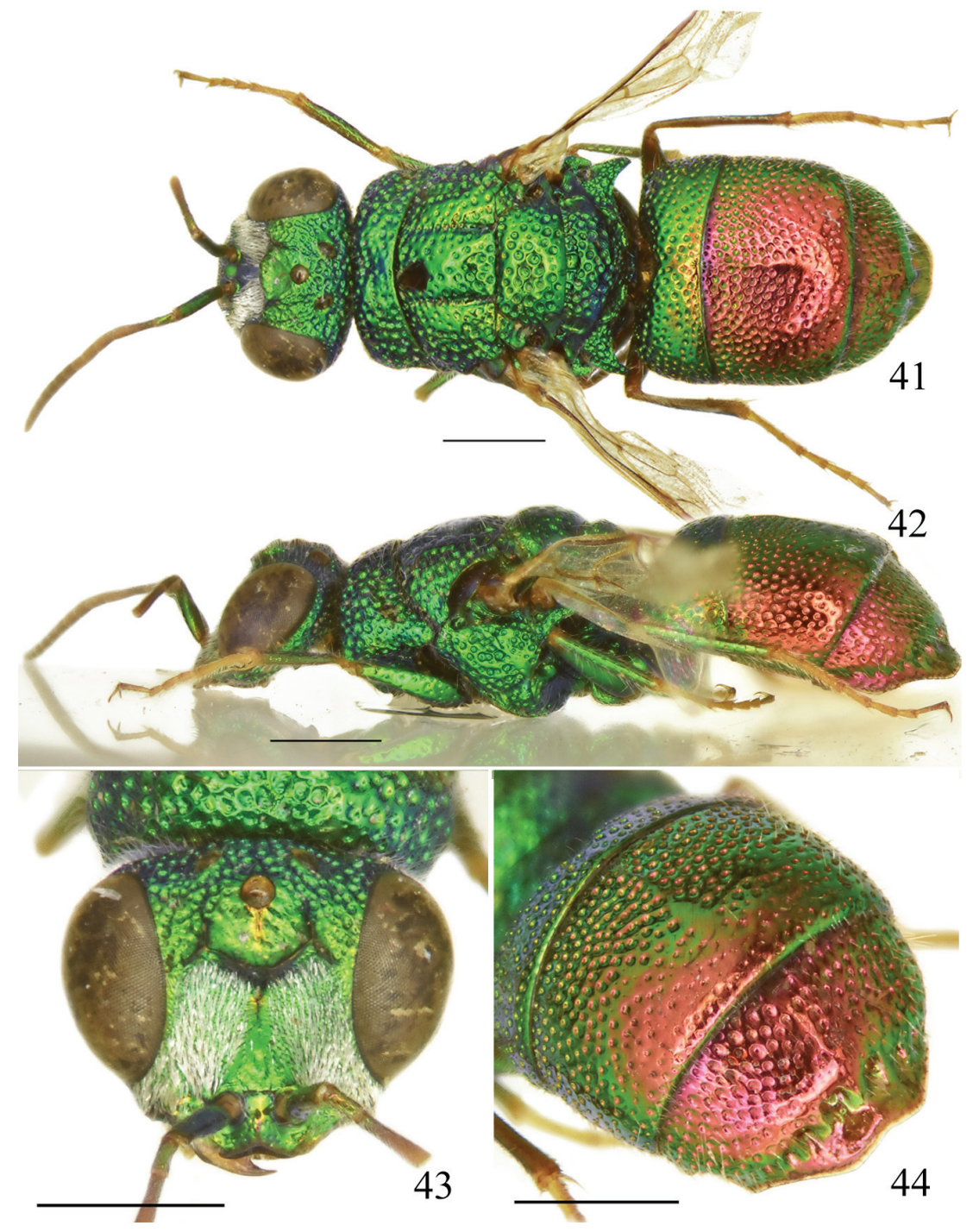

Figs 41-44. Chrysis diadema Rosa, sp. n., holotype $\widehat{o}: 41$ - habitus, dorsal view; $42-$ habitus, lateral view; 43 - head, frontal view; 44 - metasoma, dorso-lateral view. Scale bar $=$ $1.0 \mathrm{~mm}$. 
Head. In full face view, length $1.6 \mathrm{~mm}$, width $2.1 \mathrm{~mm}$. Apex of clypeus concave, medially angulate, with darkened rim; TFC sharp, raised as a crown and M-like, with elongate branches almost encircling mid ocellus; TFC medially distinctly raised and, in dorsal view, prominent, medially bilobate; mid-ocellar area, within TFC branches, largely impunctate; scapal basin distinctly hollowed, basomedially polished, laterally densely minutely punctured, with short, silvery, appressed setae covering the surface; frons and vertex with medium-sized, subcontiguous to confluent punctures. Malar spaces almost 1.0 MOD, as long as one third of F1, slightly convergent. Subantennal distance less than 1.0 MOD. Genal carina complete and extending to mandible joint, malar spaces finely punctate.

Mesosoma. Length $2.9 \mathrm{~mm}$; width (PPW) $2.2 \mathrm{~mm}$. Pronotum anteromedially depressed; depression deep and wide, reaching almost posterior margin, without a distinct anteromedian groove; punctation shallow and subreticulate, with tiny punctures on interstices; punctures denser laterally. Mesoscutum with small to mediumsized punctures, larger towards scutellum; punctation scattered, with large, polished, shining interstices; punctation irregular on lateral lobes, close to tegulae; notauli and parapsidal lines complete; notaular area depressed, apically with shallow pits. Mesoscutellum with punctures of different size, from small to medium-sized $(0.5$ MOD), the larger medially; punctures smaller and denser towards axillary trough; polished interstices. Punctation on metanotum denser, subreticulate with a row of elongate and contiguous foveae on anterior margin. Punctation on mesopleuron irregular, with small, scattered punctures, anteriorly subconfluent; episternal sulcus incomplete, formed by a few larger foveae. Propodeal teeth quite unusual, long, spike-shaped, pointing backwards and only slightly outwards.

Metasoma. Length $3.0 \mathrm{~mm}$. Punctation on first tergum with small and scattered punctures, 1-3 PD apart; small punctures on interstices. Second tergum anteriorly with larger punctures $(0.5 \mathrm{MOD})$, markedly deep and continuous, posteriorly shallow, smaller and scattered; moderate longitudinal median carina. Third tergum with deep, medium-sized punctures, laterally subcontiguous, interspersed by small and minute punctures; longitudinal median carina; apical margin with a narrow apical hyaline rim and with inner teeth replaced by broadly rounded, separated by a concave, slightly angulate medial space, lateral angles blunt, very obtuse; pits of the pit row deep, elongate, and partially confluent, medial ones as large as midocellus; post pit row area more than 1.0 MOD long; black spots on second sternum subquadrate, smaller than other species in this group, covering about $1 / 3$ of the sternum length, medially separated by $2.0 \mathrm{MOD}$.

Coloration. Head and mesosoma brilliant green; metasoma red, on first tergum and laterally coppery to green. Body ventrally green, with coppery to reddish reflections on sterna. Mandibles light brown, with metallic green reflections at base and darkened apex. Scape, pedicel and F1 basally metallic green, the latter apically black, F2-F4 light brown, F5-F11 darkened. Legs green, with joints and tarsi yellowish, last tarsomere brown. Tegulae metallic green. Wings hyaline with light brown nervures. 
Vestiture. Body covered by sparse, short (1.0 MOD), whitish, erect setae; scapal basin laterally with short, whitish and appressed setae; tibiae with longer erect setae.

Female. Unknown.

DISTRIBUTION. Turkmenistan.

ETYMOLOGY. The specific epithet diadema (= crown, feminine noun in apposition) refers to the distinctive transverse frontal carina, raised as a crown or diadem.

\section{ACKNOWLEDGEMENTS}

I am very grateful to S.A. Belokobylskij (ZIN) for the loan of unidentified material for identification; D. A. Milko (Bishkek, Kyrgyzstan), for his help during the examination of Tarbinsky's collection; M. Pavesi (Milan, Italy) and A.S. Lelej (Vladivostok, Russia) for review of the manuscript.

\section{REFERENCES}

Kimsey, L.S. \& Bohart, R.M. 1991(1990). The Chrysidid Wasps of the World. Oxford Press, New York. 652 pp.

Linsenmaier, W. 1959. Revision der Familie Chrysididae (Hymenoptera) mit besonderer Berücksichtigung der europäischen Spezies. Mitteilungen der Schweizerischen Entomologischen Gesellschaft, 32(1): 1-232.

Linsenmaier, W. 1968. Revision der Familie Chrysididae (Hymenoptera). Zweiter Nachtrag. Mitteilungen der Schweizerischen Entomologischen Gesellschaft, 41(1-4): 1-144.

Rosa, P. 2018. New records of cuckoo wasps (Hymenoptera, Chrysididae) from Russia with taxonomic notes. Far Eastern Entomologist, 360: 1-14. DOI: https://doi.org/10.25221/ fee. 360.1

Rosa, P., Antropov, A.V. \& Xu, Z.-f. 2015. A catalogue of the Chrysididae (Insecta, Hymenoptera) types deposited in the Zoological Museum, Moscow Lomonosov State University, Russia. Zootaxa, 3990(1): 1-31. DOI: http://dx.doi.org/10.11646/zootaxa.3990.1.1

Rosa, P., Belokobylskij, S.A. \& Zaytseva, L.A. 2017c. The Chrysididae types described by Semenov-Tian-Shanskij and deposited at the Zoological Institute of the Russian Academy of Sciences, Saint Petersburg (Insecta, Hymenoptera). Proceedings of the Zoological Institute RAS, Supplement 5: 1-266.

Rosa, P., Lelej, A.S., Belokobylskij, S.A., Loktionov, V.M. \& Zaytseva, L.A. 2017h. Family Chrysididae. P. 126-144. In: Lelej, A.S., Proshchalykin, M.Yu. \& Loktionov, V.M. (Eds.), Annotated catalogue of the Hymenoptera of Russia. Volume 1. Symphyta and Apocrita: Aculeata. Russkaya kollektsia SPb, St Petersburg. 475 pp.

Rosa, P., Lelej, A.S. \& Pavesi, M. 2017f. A new synonymy of Hedychridium rossicum Gussakovskij, $1948=H$. valesiense Linsenmaier, 1959, syn. n. (Hymenoptera: Chrysididae). Far Eastern Entomologist, 344: 7-9. DOI: https://doi.org/10.25221/fee.344.2

Rosa,P., Lelej, A.S., Proshchalykin, M.Yu., Loktionov. V.M. \& Mokrousov,M.V. 2017g. New records of Chrysididae (Hymenoptera) from Russia with description of five new species. Far Eastern Entomologist, 345: 1-33. DOI: https://doi.org/10.25221/fee.345.1

Rosa, P., Proshchalykin, M.Yu., Lelej, A.S. \& Loktionov, V.M. 2017d. Contribution to the Siberian Chrysididae (Hymenoptera). Part 1. Far Eastern Entomologist, 341: 1-44. DOI: https://doi.org/10.25221/fee.341.1 
Rosa, P., Proshchalykin, M.Yu., Lelej, A.S. \& Loktionov, V.M. 2017e. Contribution to the Siberian Chrysididae (Hymenoptera). Part 2. Far Eastern Entomologist, 342: 1-42. DOI: https://doi.org/10.25221/fee.342.1

Rosa, P., Vas, Z. \& Xu, Z.-f. 2017a. The Palaearctic types of Chrysididae (Insecta, Hymenoptera) deposited in the Hungarian Natural History Museum, Budapest. Zootaxa, 4252(1): 1-130. DOI: https://doi.org/10.11646/zootaxa.4252.1.1

Rosa, P., Zilioli, M. \& Jacobs, M. 2017b. Notes on endemic alpine chrysidids, with key to Alpine Philoctetes Abeille de Perrin, 1879 and remarks on two rarely collected species (Hymenoptera, Chrysididae). Natural History Sciences, 4(1): 9-18. DOI: https://doi.org/ $10.4081 /$ nhs.2017.325

Semenov-Tian-Shanskij, A.P. 1954. Classification of the tribe Hedychrini Mocs. (Hymenoptera, Chrysididae) and description of new species. Proceedings of the Zoological Institute, Academy of Sciences of the USSR, 15: 138-145. [In Russian]

Semenov-Tian-Shanskij, A. 1967. New species of gold wasps (Hymenoptera, Chrysididae). Trudy Zoologicheskogo Instituta Akademii Nauk SSSR, 43: 118-184. [In Russian]

Semenov-Tian-Shanskij, A. \& Nikolskaya, M.N. 1954. Cuckoo-wasps (Hymenoptera, Chrysididae) of Tajikistan. Proceedings of the Zoological Institute, Academy of Sciences of the USSR, 15: 89-137. [In Russian]

Tarbinsky, Yu.S. 2000a. The gold wasps of the genus Brugmoia (Hymenoptera, Chrysididae) of the Tien-Shan and adjacent territories. Vestnik zoologii, 34(3): 23-27 [In Russian]

Tarbinsky Yu.S. 2000b. The golden wasp genus Chrysis (gr. ignita) (Hymenoptera, Chrysididae) in Tien Shan and adjacent territories. Tethys Entomological Research, 2: 193 204. [In Russian]

Tarbinsky, Yu.S. 2001. New species of gold wasps (Hymenoptera, Chrysididae) from TienShan. Selevinia, 2001(1-4): 17-18. [In Russian]

Tarbinsky, Yu.S. 2002a. The golden wasp genus Chrysis L. (Hymenoptera, Chrysididae) in Tien Shan and adjacent territories. II. Species groups succincta, leachii, cerastens (!), taczanovskii, pallidicornis, smaragdula, elegans, subsinuata, serpentula, facialis, maculicornis, millenaris. Entomologicheskie Issledovaniya v Kirgizii, 22: 11-22. [In Russian]

Tarbinsky, Yu.S. 2002b. The golden wasp genus Chrysis L. (Hymenoptera, Chrysididae) in Tien Shan and adjacent territories. III. Species groups zaravshanica, sogdiana, aestiva, rufitarsis, pulchella, inaequalis. Entomologicheskie Issledovaniya v Kirgizii, 22: 23-30. [In Russian]

Tarbinsky, Yu.S. 2002c. The golden wasp genus Chrysis L. (Hymenoptera, Chrysididae) in Tien Shan and adjacent territories. IV. Species groups graelsii, comparata, splendidula, viridula, scutellaris. Entomologicheskie Issledovaniya v Kirgizii, 22: 31-44. [In Russian]

Tarbinsky, Yu.S. 2004. A review of the family Chrysididae (Hymenoptera) of the fauna of Tien Shan and adjacent territories. Euroasian Entomological Journal, 3(3): 243-249. 